\title{
6
}

\section{Over the Rainbow Bridge: Animals and Euthanasia}

\author{
Jessica Ison
}

Animal death 'is everywhere, and it is nowhere.'

From the outset, it might be easy to wonder what animals have to do with the question of human voluntary assisted dying (VAD). On the surface, the two issues seem disparate. Surely the killing of animals by way of a supposedly good death has nothing to do with the debates of human VAD. However, this chapter argues that there are connections, starting with the definition of euthanasia itself, which often includes animals. For example, the Merriam-Webster dictionary definition is 'the act or practice of killing or permitting the death of hopelessly sick or injured individuals (such as persons or domestic animals) in a relatively painless way for reasons of mercy..$^{2}$ In this definition animals can be individuals and euthanasia is extended to them, but only those who are domesticated. This definition begs the question, what about those animals who we do not deem eligible for, or worthy of, euthanasia? How do we decide who is allowed death by means of euthanasia?

1 Megan H Glick, 'Animal Instincts: Race, Criminality, and the Reversal of the "Human"' (2013) 65(3) American Quarterly, 645.

2 Merriam-Webster Dictionary (online at 24 June 2021) 'Euthanasia', <https://www.merriamwebster.com/dictionary/euthanasia>. 
This chapter grapples with the questions that arise from euthanising animals and whether these can be related to humans, including the questions raised above. It begins with an overview of animal studies and a very brief history of animal-human relations in the Eurocentric context. The chapter reveals that the practice of euthanising animals demonstrates significant complexities, in particular, relating to the fact that only some animals are considered worthy of this intervention. The complexities of defining animal euthanasia is one of the critical issues raised in this chapter, which opens up the question of why humans only euthanise some animals when we control nearly all animals. What of those animals who are not eligible to be euthanised, who instead are killed or slaughtered? Regardless of this distinction, the increase in pet ownership means that we must manage a considerable number of pet animals and we must consider human emotion in this process, which makes up the next section. All of this will open the discussion for the final section, which considers if we can relate animal euthanasia to human VAD.

Before delving into this topic, it may be relevant to note that many who engage with this collection will primarily be interested in human VAD. Therefore, the author assumed that, in general, most of the readers have little - if any - knowledge of the broad field loosely called animal studies. Consequently, at points, the chapter offers some of the foundations for the animal studies field, and the footnotes make a variety of suggestions for further reading. This is not to say that this chapter will be of no use for scholars in animal studies because, as the reader will see, animal euthanasia is a topic with little scholarship and therefore this chapter also makes a contribution to the field of animal studies.

It must also be noted that the sheer extent of our relationship with animals means that not all animals are covered here. In general, this chapter makes comparisons between pet animals and those who humans kill to eat. The chapter does not discuss free-living animals in cities, ${ }^{3}$ wild animals, animals exploited for entertainment ${ }^{4}$ and animals experimented on in laboratories, though they too are animals who may - or may not - be euthanised, and the question of their eligibility or otherwise could be seen as an extension of the analysis below.

3 For an analysis of so-called 'feral animals' see Fiona Probyn-Rapsey, 'Five Propositions on Ferals' (2016) 6 Feral Feminisms <https://feralfeminisms.com/five-propositions-on-ferals/>.

4 A case study for further analysis could be the giraffe Marius who was euthanised by the Copenhagen zoo, which garnered international attention compared to, for example, the number of giraffes killed in order to procure animals for zoos. 


\section{Overview of animal and human relations}

Animals are an ever-present part of human society. We have them as pets in our homes, some of us eat them, we have unwanted animals throughout our cities, we use them for experiments for medicine, we look at them for pleasure in nature (or on the television), and we interact with them in countless other scenarios. However, animals are often not seen as a legitimate consideration for study, policy or everyday acknowledgement. The academy neglected animals until the 'animal turn', ${ }^{5}$ which resulted in animals becoming considered worthy as a subject of study in an expanding field called human-animal studies, animal studies or critical animal studies. This chapter is influenced by and uses the framework of critical animal studies. ${ }^{6}$

Within the broad field of animal studies, animals and death is the topic of various publications, most notably a collection by the Animal Studies Group titled Killing Animals. ${ }^{7}$ This collection offers a diverse range of topics centred on the theme of animal killing, from Mad Cow Disease to hunting. Building on this is another notable collection titled Animal Death, which focuses on not just the killing but the death of animals. ${ }^{8}$ The diverse chapters point out that animal death is a complicated and broad topic that throws up many varied ethical and moral dilemmas.

What both collections highlight is that by far the most extensive relationship people have with animals is through eating them or their bodily excretions. The number of animals whom humans kill for food are almost impossible to comprehend. Globally, they are in the billions, but numbers vary across the research because it is impossible to account for those who die in fields, in factories or at birth. ${ }^{9}$ For a glimpse into this reality: 1,548,119 lambs were killed in Australia in June 2020 alone according to the Australian Bureau of Statistics. ${ }^{10}$ It is hard to imagine those lambs, still trying to feed from their mothers, killed in industrial

5 Kari Weil, 'A Report on the Animal Turn', (2010) 21(2) differences 1.

6 For an introductory overview see: Anthony J Nocella II et al (eds), Defining Critical Animal Studies (Peter Lang Publishing, 2014); Nik Taylor and Tania Signal (eds), Human-Animal Studies: Theorizing Animals: Re-Thinking Humanimal Relations (Brill, 2011).

7 Animal Studies Group (ed), Killing Animals (University of Illinois Press, 2006).

8 Fiona Probyn-Rapsey and Jay Johnston, Animal Death (Sydney University Press, 2013).

9 Animal Studies Group (n 7).

10 Australian Bureau of Statistics, Livestock and Meat, Australia, June 2020 (Catalogue No 7218. 0.55.001, 8 May 2020) <https://www.abs.gov.au/statistics/industry/agriculture/livestock-and-meataustralia/latest-release>. 
slaughter at such a scale. Add to this cows, chickens, pigs, sheep and sea life - who humans kill at astounding rates - and others. The effects of our industrial slaughter of animals does not end at this loss of life. Beyond this, animal agriculture is one of the key contributors to the climate crisis, with the UN urging everyone to drastically lower meat consumption in multiple reports for both the climate and health reasons. ${ }^{11}$ The impact of animal agriculture on our planet is devastating and defies the imagination.

Animal exploitation is pervasive. Indeed:

It is not just the statistics [on animals killed by humans] that are staggering but the fact that almost all areas of human life are at some point or other involved in or directly dependent on the killing of animals. ${ }^{12}$

However, this death is often not considered, or even rendered 'death' at all. In Eurocentric countries, we are generally far removed from the slaughterhouse, with most people only encountering an animal dying in situations such as hitting an animal on the road or euthanising a pet. Given the extent of animal death, one would imagine more scholarship on the topic might exist. Across the literature, the subtopic of euthanasia concerning animals is mostly only found in veterinary articles and policies. Notable exceptions are the increasing research on the emotions experienced by humans when they euthanise a pet ${ }^{13}$ and how euthanising healthy animals affects workers. ${ }^{14}$ However, an analysis of the cultural phenomenon of animal euthanasia is currently lacking.

11 For an overview see: Kip Andersen, 'The Facts', Cowspiracy: The Sustainability Secret (Web Page) $<$ http://www.cowspiracy.com/facts/>.

12 Animal Studies Group (n 7) 3.

13 For example: Cheri Barton Ross, Pet Loss and Human Emotion: A Guide to Recovery, ed. Jane Baron-Sorensen (Taylor \& Francis, 2nd ed, 2013); Patricia Morris, 'Managing Pet Owner's Guilt and Grief in Veterinary Euthanasia Encounters' (2012) 41(3) Journal of Contemporary Ethnography 3337; Karyn McKinney, 'Emotion Work of Coping with the Death of a Companion Animal' (2019) 27(1) Society \& Animals 109.

14 For example: Stephanie Frommer and Arnold Arluke, 'Loving Them to Death: Blame-Displacing Strategies of Animal Shelter Workers and Surrenderers' (1999) 7(1) Society \& Animals 1. 


\section{History of animal and human relations}

When talking about animals, people tend to make rather large claims. The history of euthanasia is no different. Indeed, most of the writing tells us more about how we perceive animals than any real historical truths - if this is even possible - about animal euthanasia. For example, Kleinfeldt claims that:
Whereas euthanasia of humans has historically been prohibited, euthanasia of animals is not an emergence of the present age, but has been performed for centuries. In ancient Egypt, it was not uncommon that at the owner's death, if his [sic] pet was still alive, the pet would be euthanized to be reunited with its [sic ${ }^{15}$ owner, so the pet could continue to be the deceased's companion in the afterlife. ${ }^{16}$

Here, Kleinfeldt frames these grand assumptions about Egyptian burial practices as euthanasia. It is worth noting that, embedded in these assumptions are views about what an animal wants and needs alongside the social and political context of burials from Ancient Egypt.

There is little else written on the history of animals and euthanasia. Therefore, to have a deep understanding of euthanasia today, we must turn to a broader analysis of animal-human relations to shed light on some of the changing attitudes that led to the euthanasia regulations we have today. As an illustrative case, a brief look at the history of animal cruelty laws provides insight into some of the ways that animalhuman relations have changed with capitalism in Eurocentric countries. The prominent example that most readers will know is the Royal Society for the Prevention of Cruelty to Animals or the RSPCA.

The RSPCA started as the SPCA in 1824 and was focused primarily on vivisection and animal cruelty enacted by the working class, such as the treatment of ponies in coal mines and cockfighting. ${ }^{17}$ That is, primarily the people organising for the SPCA were in the middle- to upper-class of

15 Throughout this chapter when animals are referred to as 'it' or 'its', this speciesist language is noted with a '[sic]'.

16 Alexandra Kleinfeldt, 'Brief Summary of Animal Euthanasia', Animal Legal \& Historical Center (Web Page, 2017) <https://www.animallaw.info/article/brief-summary-animal-euthanasia>.

17 Josephine Donovan and Carol J Adams (eds), The Feminist Care Tradition in Animal Ethics: A Reader (Columbia University Press, 2007); Lyle Munro, Compassionate Beasts: The Quest for Animal Rights (Praeger, 2001). 
British society. Queen Victoria decided to give patronage to the SPCA in 1937, which saw the addition of Royal to the name. ${ }^{18}$ The formation of the RSPCA is a crucial moment in Eurocentric animal rights movements. In the Victorian era, society closely tied animals to moral and political issues, particularly concerning controlling the working class, which was also influenced by Christianity and the morals of the church. ${ }^{19}$ The use of animals in moral crusades is still prevalent today, easily seen in the supposed care for animals in live export. ${ }^{20}$ Humans use animals in every conceivable way, including politically.

Returning to earlier examples, a case in point of the earlier use of animals for political gains was in the 1800s when the first animal protection legislation begins to emerge in Europe. Indeed, the 'First [animal rights] bill to be brought in Parliament was introduced by Sir William Pulteney in 1800 to end bullbaiting. ${ }^{21}$ The Bill may seem like a positive development with regard to human concern for animals, but generally, it is understood that bullbaiting was something the working classes also enjoyed. The bill passed in 1822, titled Prevent the Cruel Treatment of Cattle, which was the first legal protection for animals in Britain..$^{22}$ Following this line of critique, it is significant to note that the cruelty that the upper classes called sport, such as fox hunting, was not on the agenda. Indeed, nor was the killing of cows or other animals for food.

The creation of the RSPCA and the various animal cruelty bills passed in British parliament show, on the surface at least, that there was care for animals and distaste for animal cruelty, albeit usually intertwined with the practices of the working class. Once who was being targeted by the different legislation is considered, it becomes clear that animals were a tool for control and criminalisation. Care for animals, as is shown throughout this chapter, is rarely about the animals themselves. ${ }^{23}$ Victorian literature scholars Laurence Mazzeno and Ronald Morrison take this point further to argue that:

18 'Our History', RSPCA UK (Web Page) <http://www.rspca.org.uk/utilities/aboutus/history>.

19 Li Chien-Hui, 'An Unnatural Alliance? Political Radicalism and the Animal Defence Movement in Late Victorian and Edwardian Britain' (2012) 42(1) EurAmerica 1.

20 The uproar about these abused animals not only obscured the cruelty animals face in Australia but it was generally thinly veiled racism about how supposedly Australian animals were treated overseas. For further analysis see Nick Pendergrast, 'Live Animal Export, Humane Slaughter and Media Hegemony' (2015) 4(1) Animal Studies Journal 99.

21 David Perkins, Romanticism and Animal Rights (Cambridge University Press, 2003) 17.

22 Ibid, 16.

23 Jessica Ison, 'Animal Abuse and Advocating for the Carceral: Critiquing Animal Abuse Registries' (2019) 8(2) Animal Studies Journal 55. 
At another level, these issues also became the means for Victorian culture to consider the shifting boundaries of social class, the expansion and maintenance of the British Empire, and the benefits and challenges created by the development of modern science, including ethical challenges posed by Darwinism. ${ }^{24}$

Mazzeno and Morrison support the argument that social class was a crucial factor in legislation concerned with animals. It is clear that how humans treat animals reflects changes in culture and social attitudes. Humananimal relations were arguably altered forever because of the English naturalist and founder of evolutionary theory, Charles Darwin. ${ }^{25}$ People started to view the natural world in an entirely different way and, based on hitherto unimagined closeness between humans and other animals (such as apes), humanity began to develop a capacity for thinking about animals differently. ${ }^{26}$ It follows that this impacted views on animal death.

With this as background, it is significant that alongside the creation of animal cruelty laws was the creation of the slaughterhouse. In the context of understanding the significance of the slaughterhouse for global capitalism, critical animal studies scholar Nicole Shukin draws our attention to the oftenforgotten fact that Ford took his model for production lines from abattoirs. Shukin dates the slaughterhouse production line to at least the $1850 \mathrm{~s}^{27}$ She points out that the slaughterhouse presents the first (dis)assembly line and questions the fact that analysis of capitalism often neglects this history. The rendering of a live animal into meat for consumption at such a fast pace would simply be impossible for a single worker, and so necessitates something like the slaughterhouse, that functions by breaking the work into specific tasks. This rendering of so many animals into meat also could not be tolerated psychologically by individuals, and so the production line took the onus of killing off any one person. ${ }^{28}$

24 Laurence W Mazzeno and Ronald D Morrison, 'Introduction' in Laurence W Mazzeno and Ronald D Morrison (eds), Animals in Victorian Literature and Culture: Contexts for Criticism (Palgrave Macmillan UK, 2017) 2.

25 Jed Mayer, 'Ways of Reading Animals in Victorian Literature, Culture and Science' (2010) 7(5) Literature Compass 348.

26 While out of scope for this chapter, the abuse of animals was also central to the colonial processes at the time and animals were (and are) used in a variety of ways to create discourses of white supremacy. The relationship of human to apes for example, played into racial hierarchies in some particularly heinous ways. See: Claire Jean Kim, Dangerous Crossings: Race, Species, and Nature in a Multicultural Age (Cambridge University Press, 2015).

27 Nicole Shukin, Animal Capital: Rendering Life in Biopolitical Times (University of Minnesota Press, 2009).

28 Timothy Pachirat, Every Twelve Seconds: Industrialized Slanghter and the Politics of Sight (Yale University Press, 2011). 
Not only were these slaughterhouses places of intense animal cruelty, worker exploitation and pollution, they were also in fact places of entertainment:

Tours of slaughterhouses, already a popular sideline of Chicago's Packing town as early as the 1860s, were designed to showcase the tremendous efficiency with which American culture managed its material nature. Slaughterhouse tourism also promised to fascinate and disturb tour-goers with the somatic sights, smells, and sounds - the 'physiological trials' - of doomed animals and gore covered laborers. ${ }^{29}$

As this analysis shows, there exists then an incredible tension between animals and humans, emerging from this period where people supposedly began to care about the wellbeing of animals. This closer look reveals a more complex combination of the interplay of interests, including providing a way to control the working class in a period of the sharp increase in the exploitation of animal's bodies.

This contradiction of animal welfare and animal exploitation that increased during industrialisation was also mirrored by the presence of animals in people's homes as pets.

Since the nineteenth century, there has been a particular split between domesticated farm animals and domesticated house animals. Today, few Westerners have daily contact with working animals or those destined to be eaten. ${ }^{30}$

The increase in friendship between animals often obscures the realities of how many animals are killed by humans.

The shifting relationship with animals in the twentieth century saw the rise of the pet industry. To understand this shift, Bulliet argues that there is a domestic and a postdomestic era concerning animals, with the latter beginning in the 1970s:

A postdomestic society emerging from domestic antecedents continues to consume animal products in abundance, but psychologically, its members experience feelings of guilt, shame,

29 Shukin (n 27) 94.

30 Matthew Wills, 'The Invention of Pets', JSTOR Daily (Blog Post, 28 January 2017) <https://daily. jstor.org/the-invention-of-pets/>. 
and disgust when they think (as seldom as possible) about the industrial processes by which domestic animals are rendered into products and about how those products come to market. ${ }^{31}$

While the 1970s is perhaps a little late for this distinction - the turn of the century or even earlier seems to be more accurate given the above history - the separation between domestic and postdomestic is useful. In the postdomestic era, people somewhat contradictorily became close to their pets, even to the point of seeing them as part of their family, while being further separated from other animals. ${ }^{32}$ In this way, pets become a kind of in-between animal, who we afford certain levels of care and treatment to that was hitherto unavailable to animals, and which expanded the discourse on animal cruelty for this group of animals. This closeness opened up the possibility of animals who could be euthanised, not just killed, which in turn needed regulation. ${ }^{33}$

\section{What is animal euthanasia in the postdomestic era?}

Currently, the killing of animals is regulated but not as strongly as one might imagine. Animal death depends on the type of animal in question. ${ }^{34}$ The specific welfare of animals in Australia is state-based under Prevention of Cruelty to Animals Acts (POCTAs). Given that the vast majority of animals are raised to be killed in Australia, there is a Code of Practice for how to care for and kill these animals. Under POCTAs, killing an animal will in many circumstances constitute cruelty, and therefore POCTAs cannot relate to those animals humans eat because killing them would be illegal. To circumvent this problem, the POCTAs have exceptions. For instance, in the state of Victoria, the Prevention of Cruelty to Animals

31 Richard Bulliet, Hunters, Herders and Hamburgers: The Past and Future of Human-Animal Relationships (Columbia University Press, 2005) 3.

32 Amy J Fitzgerald, 'A Social History of the Slaughterhouse: From Inception to Contemporary Implications' (2010) 17(1) Human Ecology Review 59.

33 Other animals have deaths framed as euthanasia, such as racehorses who have an injury and animals for experimentation. Also, some 'pest' animals might be euthanised, though usually this will be called 'culling'. Pets are unique in their apparent position as part of the family.

34 This chapter has not touched on such issues as wild animals and the issue of culling or killing animals during a disease outbreak. 
Act 1986 does not apply to '[a]ny act or practice with respect to the farming, transport, sale or killing of any farm animal which is carried out in accordance with a Code of Practice'..$^{35}$

And further:

the keeping, treatment, handling, transportation, sale, killing, hunting, shooting, catching, trapping, netting, marking, care, use, husbandry or management of any animal or class of animals ... which is carried out in accordance with a Code of Practice. ${ }^{36}$

Within the law, there are already specific differences between certain animals. Some animals fall under the need of protection and others are simply within the Code of Practice, which is generally regulated by the industry.

Pets fall under POCTAs and therefore are one of the only groups whose deaths we deem 'euthanasia' because it does not take place in a slaughterhouse. Generally, veterinary associations regulate this practice. The Australian Veterinary Association (AVA) outlines what is considered euthanasia for veterinary purposes in Australia:

The attending veterinarian must recommend euthanasia for an animal if the animal is suffering and that suffering is not able to be adequately minimised or managed. Euthanasia is the act of inducing humane death with the minimum of pain, fear or distress to the animal involved. It is most often used with terminally unwell or injured animals, where the prognosis is considered hopeless, and should also be considered for animals with intractable behaviour problems. ${ }^{37}$

The use of the word 'suffering' is of interest because, in this outline, euthanasia is in the best interest of an animal who cannot speak for themselves. ${ }^{38}$ Therefore, the vet consults with the 'owner' of the animal. Often those animals who are domesticated but who do not have an owner will be killed by euthanasia in pounds.

35 Prevention of Cruelty to Animals Act 1986 (Vic) s 11.

36 Ibid.

37 'Euthanasia', Australian Veterinary Association (Web Page, 10 August 2007) <https://www.ava. com.au/policy/44-euthanasia>.

38 Writing about animals offers a range of issues relating to language, particularly when also avoiding gendering animals. 'Themself' or 'themselves' is one tactic for challenging the way that English creates animals as objects through the use of 'it' or similar. 
The AVA also outlined some of the broad definitions of euthanasia for their purposes:

- 'the process of inducing a painless death'39

- 'the humane killing of an animal, in the interests of its [sic] own welfare, to alleviate pain and distress' 40

- 'a gentle death ... regarded as an act of humane killing with the minimum of pain, fear and distress' ${ }^{41}$

There are definitive differences in these definitions, most notably that only one seems to outline that euthanasia is to 'alleviate pain and distress', whereas the other descriptions offered are about the process of euthanasia. Veterinary scientist Anne Fawcett questions these definitions and also highlights how the American Veterinary Medical Association's definition is specifically about the killing of the animals, not about the intentionality behind this killing, stating "it seems that the term "euthanasia", where animals are concerned, is synonymous with any death effected by a veterinarian'. ${ }^{42}$ There is a difference here between the laws in various countries, and how the death of the animal is understood. Fawcett voices this as a concern about 'what indeed euthanasia actually is, if animals who are not suffering are killed'. ${ }^{43}$ In particular, Fawcett is referring to pet animals killed in pounds though this same observation could apply to pet animals whom a veterinarian euthanises because their owners can no longer look after them, or no longer wants them. Perhaps one of the critical issues is that there are so many different types of animals, here only some domesticated animals have been discussed.

39 JS Reilly (ed), Euthanasia of Animals Used for Scientific Purposes, ed JS Reilly (Australian \& New Zealand Council for the Care of Animals in Research and Teaching, 2nd ed, 2001), cited in 'Euthanasia' (n 37).

40 National Health and Medical Research Council, Australian Code of Practice for the Care and Use of Animals for Scientific Purposes (Report, 7th ed, 2004), cited in 'Euthanasia' (n 37).

41 European Commission, Euthanasia of Experimental Animals (March 1997), cited in 'Euthanasia' (n 37).

42 Anne Fawcett, 'Euthanasia and Morally Justified Killing in a Veterinary Clinical Context' in Jay Johnston and Fiona Probyn-Rapsey (eds), Animal Death (Sydney University Press, 2013) 208.

43 Ibid, 209. 
Not all perspectives on euthanasia come from the law or veterinarians. Some activists and scholars weigh in on this debate to generally outline an ideal situation for animals within a welfare or rights framework. ${ }^{44}$ For example, animal studies scholar Tom Regan proposed the following rules:

1. Killing must be by the most painless means possible;

2. That it must be believed to be in the animal's best interests and this must be a true belief;

3. One who kills must be motivated by concern for the interest, good or welfare of the animal involved. ${ }^{45}$

This definition comes from a very different perspective to those writing from a veterinary or industry agenda because it does not relate to just pet animals, but to all animals. Regan is writing from a perspective where euthanasia is only in the service of helping the animal, and therefore killing of animals in pounds could perhaps not be euthanasia. For Regan, this is 'preference respecting euthanasia'.

Regan has some resonance with Catherine Tiplady, who writes about animal abuse, and in relation to euthanasia states that:

\begin{abstract}
Where there is uncertainty whether to attempt treatment, continue treatment or euthanize, it is advisable to arrange a meeting of all members of the animal care team so everyone can discuss the patient, express their concerns and reach a consensus about the options for this animal. ${ }^{46}$
\end{abstract}

44 There is a distinct difference between those who advocate for animal welfare and those who advocate for animal rights. To put it simply, welfare advocates would argue that chickens should have bigger cages and rights advocates would say no animals should ever be caged for human use. On top of this, abolitionist or total liberationists might argue that no animal should ever be used or harmed by humans. Total liberation might also be paired with other politics that advocate for intersectionality. For more information see: Sarat Colling, Sean Parson, and Alessandro Arrigoni, 'Until All Are Free: Total Liberation through Revolutionary Decolonization, Groundless Solidarity, and a Relationship Framework' in Anthony J Nocella II et al (eds), Defining Critical Animal Studies: An Intersectional Social Justice Approach for Liberation (Peter Lang Publishing, 2014); David N Pellow, Total Liberation: The Power and the Promise of Animal Rights and the Radical Earth Moment (University of Minnesota Press, 2014); Richard Twine, 'Intersectional Disgust? Animals and (Eco)Feminism' (2010) 20(3) Feminism \& Psychology 397.

45 Tom Regan, The Case for Animal Rights (Routledge \& Kegan Paul, 1983).

46 Catherine Tiplady, Animal Abuse: Helping Animals and People (CABI, 2013) 164. 
Here the animal is to be spoken for, yet it is not clear how one consults the animal, a problem that is also present in Regan's argument. Tiplady then goes on to outline the method for euthanasia drawing from Wolfensohn and Lloyd's ${ }^{47}$ rules for laboratory animals:

1. Death must occur without producing pain. 2. The time required to produce loss of consciousness must be as short as possible. 3. The time required to produce death must be as short as possible. 4. The method must be reliable and nonreversible. 5. There must be minimal psychological stress on the animal. 6. There must be minimal psychological stress to the operators and observers. 7. It must be safe for personnel carrying out the procedure. 8. Any drugs used should be readily available and have minimum abuse potential. 9. The method should be economically acceptable. 10. It should be simple to carry out, with little room for error. ${ }^{48}$

This outline is unique in that it takes into account the impact euthanising could have on the workers, surely a topic worthy of an entire paper. ${ }^{49}$

A more recent proposition, from a legal and animal protection perspective, is Janice H Cox and Sabine Lennkh's Model Animal Welfare Act, ${ }^{50}$ which they specifically designed to be a 'basic template and guidance document for those interested in enacting new legislation or improving existing animal protection legislation'. ${ }^{51}$ In this extensive document, there is no section on euthanasia. The closest they come to euthanasia is 'Section 20 Humane Killing and Slaughter of Animals' where they state:

the killing of an animal has at all times to be carried out in compliance with the subject Act as well as in a humane way and in such a manner that the animal is spared any avoidable pain, suffering, injury, fear or distress. ${ }^{52}$

47 Sarah Wolfensohn and Maggie Lloyd, Handbook of Laboratory Animal Management and Welfare (Blackwell Science, 2nd ed, 1998) 49-51.

48 Tiplady (n 46) 166.

49 Veterinarians in fact have high rates of suicide that has been attributed to multiple issues, one being the high rates of having to euthanise healthy animals. For further information see: 'Suicide', Australian Veterinary Association (Web Page) <https://www.ava.com.au/member-services/vethealth/suicide/>.

50 Janice Cox and Sabine Lennkh, Model Animal Welfare Act: A Comprehensive Framework Law (World Animal Net, 2016).

51 Ibid.

52 Ibid, 57. 
While this appears to be a reasonable argument, they still couch it within a section that is about the killing and slaughter of animals. There is little differentiation between animals and no critical engagement with why some animals are only killable because they will become food.

Many cases of euthanising animals would not fit any of the more animal welfarist or rights-based definitions of euthanasia. Fawcett goes so far as to claim:

In reality, the killing of an animal is often not a case of 'euthanasia', no matter how painless, dignified and legally sanctioned that happens to be, because the interests of the animal are not served. ${ }^{53}$

Fawcett is specifically referring to the killing of animals in pounds, where euthanasia is most commonly associated. While these statistics of animals in pounds are hard to gather, Animals Australia claims that pounds in Australia kill hundreds of thousands of animals each year. ${ }^{54}$ The RSPCA does not admit to killing any 'excess' animals; however, their statistics have a surprisingly high number killed for 'behavioural issues', which they do not explain. ${ }^{55}$ There are more studies on pounds in the US and they tend to say that each year pounds kill millions of animals. ${ }^{56}$ These numbers indicate a disconnect between those animals we say we love and their actual treatment. So as Palmer argues:

alongside the social recognition of cats and dogs as companions and family members lies the social treatment of them as expendable individuals that can be killed en masse at human will - or even whim..$^{57}$

The killing of so many dogs and cats brings in to question our supposed love for pets. How do we kill so many pet animals and yet we see some animals as a member of the family?

53 Fawcett (n 42) 208.

54 'Companion Animals', Animals Australia (Web Page, 13 August 2019) <https://www.animals australia.org/issues/companion_animals.php>.

55 RSPCA Australia, RSPCA Australia National Statistics 2019-2020 (Report) <https://www.rspca. org.au/sites/default/files/RSPCA\%20Australia\%20Annual\%20Statistics\%202019-2020.pdf>.

56 'Statistics', No Kill Advocacy Center (Web Page) <https://www.nokilladvocacycenter.org/statistics. html>.

57 Clare Palmer, 'Killing Animals in Animal Shelters' in Animal Studies Group (ed), Killing Animals (University of Illinois Press, 2006) 171. 


\section{Humane killing}

A growing part of euthanising animals concerns the single beloved pet, often framed in terms of compassion and love for the animal. Such as a popular website that notes, ' $[\mathrm{h}]$ aving to make the decision to end a pets [sic] life is the ultimate act of love, however, this in turn brings enormous feelings of guilt'. ${ }^{58}$ As a result of this guilt, there is increased awareness of human emotions. Therefore, part of the euthanising of animals is mitigating the human emotions by sanitising the death of the animal. For example, the large animal welfare service in the US is called The Humane Society and they refer to the procedure as 'End of life services'. ${ }^{59}$ Here they are even shunning the word euthanasia, opting for a euphemism that obscures the death of a loved pet. ${ }^{60}$ The process is also expensive. It could cost thousands of dollars when an animal is sick, and the euthanasia fee can be hundreds on top of this. ${ }^{61}$ Death becomes a commodity that one must pay for, yet one might chose it as a more cost-effective intervention than other treatments for a sick animal. This sanitised and commodified approach to death is an interesting and confusing reality when billions of animals are killed every year by humans, and yet some are afforded a death in a clinic, or even a home visit from a vet, and given a burial.

A flow-on problem with so many pet animals is what to do with their bodies (which is a concern with humans too). In major cities, this is a problem because people might not have backyards in which to bury them. ${ }^{62}$ However, a backyard burial can also be a problematic choice because of the chemicals used in euthanising animals, which can have an impact on the environment or could poison an animal who digs up and

58 'When is the Right Time for Euthanasia?', Living With Pet Bereavement (Web Page) <https:// livingwithpetbereavement.com/is-the-time-right $\% 3 \mathrm{~F}>$.

59 'End-of-Life Services', Animal Humane Society (Web Page) <https://www.animalhumanesociety. org/health/end-life-services>.

60 In fact, when this chapter was being finalised there was an article circulating on social media about euthanising kangaroos 'humanely' to make way for a development in Perth, which begs the question: is this really in the best interest of the animals? Lauren Pilat, "Humanely Euthanised": Roos to Be Killed to Make Way for Development South of Perth', WA Today (online, 28 January 2019) $<$ https://www.watoday.com.au/national/western-australia/humanely-euthanised-roos-to-be-killedto-make-way-for-development-south-of-perth-20190128-p50u4u.html>.

61 The cost across a range of veterinary websites is from $A \$ 50-A \$ 300$ for euthanasia.

62 Yi Zhu and Min Liu, 'Discussion of the Metropolis Pet Funeral and Burial Service', in Ying Zhang (ed.), Future Communication, Computing, Control and Management: Volume 2 (Springer Berlin Heidelberg, 2012) 267. 
eats the body. ${ }^{63}$ Another option is to have a pet buried in a pet cemetery. Archaeologists have found animal remains in what could be a burial ritual as far back as the Neolithic period. ${ }^{64}$ Pet cemeteries as we have them today have their origin in the nineteenth century in Europe. ${ }^{65}$ With the rise of the middle-class pet ownership and the increase in urbanisation, dealing with the body of pets became a problem.

Not surprisingly, the first official establishment of this kind were created on the outskirts of two bustling metropolises of the world New York (Hartsdale Pet Cemetery, est. 1896) and Paris (Cimetière des Chiens et Autres Animaux Domestiques, est. 1899). ${ }^{66}$

Yet again, when looking at pet cemeteries, we see this distinction between those who we supposedly love and those who are merely animals we use, because '[c]rucially, pet cemeteries are for pets, not for animals more generally' ${ }^{67}$ As noted above, often this way of expressing care for animals is not extended to all animals who can be pets because dogs and cats are killed in the millions every year in pounds. Perhaps there are parallels here with humans, where humans in death are clearly not treated equally. Money determines how we deal with a body after death.

This contradiction of an increased sanitised death and the burial of some animals in a world with industrial slaughterhouses raises many issues. Returning one last time to the AVA's description of euthanasia, they also state:

The necessary killing of animals for other reasons [such as slaughterhouses, laboratories] should not be confused with euthanasia, although the methods used and the principles to apply are the same. ${ }^{68}$

63 Rachel Allavena, 'Why You Shouldn't Bury Your Pet in the Backyard' ABC News (online, 19 March 2019) <https:/www.abc.net.au/news/2019-03-19/why-you-shouldn\%E2\%80\%99t-bury-your-pet-inthe-backyard/10915772>.

64 Ivy D Collier, 'More Than a Bag of Bones: A History of Animal Burials' in Margo DeMello (ed), Mourning Animals: Rituals and Practices Surrounding Animal Death (Michigan State University Press, 2016).

65 Hilda Kean, 'Human and Animal Space in Historic "Pet" Cemeteries in London, New York and Paris' in Jay Johnston and Fiona Probyn-Rapsey (eds), Animal Death (Sydney University Press, 2013). 66 Michał Piotr Pręgowski, 'All the World and a Little Bit More: Pet Cemetery Practices and Contemporary Relations between Humans and Their Companion Animals' in Margo DeMello (ed), Mourning Animals: Rituals and Practices Surrounding Animal Death (Michigan State University Press, 2016).

67 Jane C Desmond, Displaying Death and Animating Life: Human-Animal Relations in Art, Science, and Everyday Life (University of Chicago Press, 2016).

68 'Euthanasia' (n 37). 
The policy then outlines what supposedly necessary killings are. They make a specific distinction between those animals who are to be euthanised and those who are to be killed. With such a stark line drawn between those who are allowed to be euthanised and those who are killed, the ethics of euthanasia becomes even murkier.

What would it mean to euthanise a cow? Or to euthanise a chicken? Outside of animal liberation circles, this may seem preposterous as those animals are only allowed to live to be eaten. ${ }^{69}$ Therefore, we draw a line where we deem some animals as not worthy of being euthanised because they are not enveloped within the circle of human concern and are rather a product to be consumed. Or perhaps it is that some animals are deemed worthy of being euthanised. If euthanasia really is just about giving a pleasant death (a contention debated throughout this collection), then we should also consider who can access this death. As we have seen through the consideration of animal euthanasia, a crucial consideration here is who - and who is not - deemed worthy of accessing a pleasant death, what criteria do we use to determine this, and who ultimately chooses.

\section{Can this be related to humans?}

This chapter does not intend to draw parallels between animals and humans in a crude sense; that has been done, and it has rarely been done well. ${ }^{70}$ However, we can draw some analysis between those animals we euthanise and those we kill and how this can be related to the arguments around VAD for humans.

Animals and euthanasia is framed as offering comfort in death but often only given to those we supposedly love. And yet, in general, every facet of animal life is controlled, and their exploitation is infinite. Animal studies scholar Dinesh Wadiwel frames this point as a 'war against animals' that

69 There is not space here to talk about animals and mourning but this is also an important aspect; groups such as Animal Liberation Victoria hold public memorials for dead animals. Animal Rights, 'Animals Are Not Ours Memorial', Vimeo (Video, 7 October 2013) <https://vimeo.com/76382879>. 70 There are many animal studies scholars who have engaged with multiple issues in a critical and nuanced way, such as: Esther Alloun, “"That's the Beauty of It, It's Very Simple!” Animal Rights and Settler Colonialism in Palestine-Israel' (2018) 8(4) Settler Colonial Studies 559; Amie Breeze Harper (ed), Sistah Vegan: Black Female Vegans Speak on Food, Identity, Health, and Society (Lantern Books, 2010); Jessica Ison and JL Schatz, 'Introduction: Queering the Ecofeminist Tradition' (2016) 9(3) Green Theory \& Praxis Journal 4; Kim (n 26). 
is ever-present and total. ${ }^{71}$ Critical race scholar Megan $\mathrm{H}$ Glick calls this ever-present control and death as 'normalizable' because the system is so pervasive. ${ }^{72}$ When you consider animals, there are few - if any - who are not in some way controlled or managed by humans. We may frame euthanasia as care for animals, but the extent of those who we kill and the reasons for this killing shows that it is too a form of animal management. By talking sweetly of one's dog crossing the rainbow bridge, waiting for us in heaven as they drift off to sleep in the veterinary clinic, we forget those who we kill in pounds, the slaughterhouse rolls on and the less benign reasons for choosing euthanasia on behalf of a pet are ignored - such as the cost of keeping the pet or that they have become too burdensome.

Animals also show us that we presume to understand the subject who cannot speak for themself. Dying a good death is presumed to be the most desired outcome, after living a good life. However, the presumption of what a good death is, particularly concerning animals, is premised on knowing them in a relationship where humans have complete management and control. If we forgo the presumption that we know what a good death is for animals, we may have to begin to question what is a good life. Animal euthanasia happens so often, to such an unfathomable degree, that assurance of this being a 'good death' obfuscates the reality of the extent of these supposed good deaths. The animals who cannot speak for themselves, at least not in a language we bother to learn, have a good death forced on them. Inevitably, this is a concern for those humans who also cannot advocate for themselves. Who says what a good death is?

The crucial difference between the management of human death and animal death is that we do not - for the most part - eat humans. ${ }^{73}$ Even further, we breed some animals to eat them. We bring them into this world for this purpose. Indeed, if they do not fulfil this purpose we kill them, such as roosters or bobby calves who are respectively thrown into macerators alive or taken from their mothers and kept in a tiny cage for a few weeks before slaughter. These animals show the stark cruelty of this industry and also the depths to which we wave our concern for

71 Dinesh Joseph Wadiwel, The War Against Animals (Brill Rodophi Press, 2015).

72 Megan H Glick, 'Animal Instincts: Race, Criminality, and the Reversal of the "Human"' (2013) 65(3) American Quarterly, 645.

73 Though an argument could be made that we do consume humans and human life through exploitation and the control of workers under the capitalist system. Could consumption be extended to slavery and indentured servitude? Or in a different vein, what of the woman consumed by a violent relationship? At what point is the human consumable even if they are not edible? 
the vulnerable. A society that throws live chicks into plastic bags to die must surely not be one that has pet cemeteries. Nevertheless, this contradiction exists.

Due to this contradiction, our opinions on how they should die offer an interesting insight into how we conceive of life and who indeed we conceive of as living a life. If we have such stark separation between animals we love and animals we exploit, then perhaps we can question whether this relates to humans. However, what even constitutes the human? Indeed, 'the human as a category is frequently taken for granted, though it remains deeply tied to political and juridical notions of enfranchisement and belonging. ${ }^{74}$ Those who have access to being seen as fully human are a privileged few. With VAD will we see some people allowed to access a supposedly peaceful death and others left to suffer? The legal issues and access to knowledge will surely prohibit many humans from accessing VAD. What might the study of animals and their deaths, considerations of who and who is not enveloped in a circle of care, and the question of who determines what constitutes a 'peaceful death', how that is administered and by whom, teach us that may be relevant for human VAD? If nothing else, it shows us that we can construct elaborate layers of meaning that obfuscate cruelty and solidify a moral and ethical position that refuses to engage with the myriad inconvenient concerns.

\section{Conclusion}

VAD raises a slew of moral concerns, many of which this collection addresses. Yet people often believe it is simply a case of allowing someone to die painlessly. Even if it was this simple - which this collection definitively shows it is not - it is still a matter of who we see as worthy of having a good life. Over and again, whom we include and whom we exclude from available treatments obscures a series of social issues. Those animals left in pounds are not able to have a human speak for them, and for a variety of reasons, veterinarians often euthanise healthy animals. They are not able to access the wealth of those animals who get to live well because of their categorisation as 'pets'. In this society, it seems that only those who we extend care to in life are granted care in death. The debate then must shift away from the ethics of dying by choice, to the ethics of who is 
deemed worthy of care in both death and life. Our complicated relations with animals can teach us that we have the capacity for great love and care but also for allowing death to become something that is managed within a system of exploitation that only allows some to die well, particularly when they were allowed to live well.

\section{Bibliography}

\section{A Articles/books/reports}

Alloun, Esther, “'That's the Beauty of It, It's Very Simple!" Animal Rights and Settler Colonialism in Palestine-Israel' (2018) 8(4) Settler Colonial Studies 559 doi.org/10.1080/2201473X.2017.1414138

Animal Studies Group, Killing Animals (University of Illinois Press, 2006)

Bulliet, Richard W, Hunters, Herders, and Hamburgers: The Past and Future of Human-Animal Relationships (Columbia University Press, 2005)

Collier, Ivy D, 'More than a Bag of Bones: A History of Animal Burials' in Margo DeMello (ed), Mourning Animals: Rituals and Practices Surrounding Animal Death (Michigan State University Press, 2016) 3

Colling, Sarat, Sean Parson and Alessandro Arrigoni, 'Until All Are Free: Total Liberation through Revolutionary Decolonization, Groundless Solidarity, and a Relationship Framework' in Anthony J Nocella II et al (eds), Defining Critical Animal Studies: An Intersectional Social Justice Approach for Liberation (Peter Lang Publishing, 2014)

Cox, Janice and Sabine Lennkh, Model Animal Welfare Act: A Comprehensive Framework Law (World Animal Net, 2016)

Desmond, Jane C, Displaying Death and Animating Life: Human-Animal Relations in Art, Science, and Everyday Life (University of Chicago Press, 2016) doi.org/ 10.7208/chicago/9780226375519.001.0001

Donovan, Josephine and Carol J Adams (eds), The Feminist Care Tradition in Animal Ethics: A Reader (Columbia University Press, 2007)

European Commission, Euthanasia of Experimental Animals (March 1997)

Fawcett, Anne, 'Euthanasia and Morally Justifiable Killing in a Veterinary Clinical Context' in Jay Johnston and Fiona Probyn-Rapsey (eds), Animal Death (Sydney University Press, 2013) 205 doi.org/10.2307/j.ctt1gxxpvf.18 
Fitzgerald, Amy J, 'A Social History of the Slaughterhouse: From Inception to Contemporary Implications' (2010) 17(1) Human Ecology Review 58

Frommer, Stephanie S and Arnold Arluke, 'Loving Them to Death: BlameDisplacing Strategies of Animal Shelter Workers and Surrenderers' (1999) 7(1) Society \& Animals 1 doi.org/10.1163/156853099X00121

Glick, Megan H, 'Animal Instincts: Race, Criminality, and the Reversal of the "Human" (2013) 65(3) American Quarterly 639 doi.org/10.1353/ aq. 2013.0046

Harper, Amie Breeze (ed), Sistah Vegan: Black Female Vegans Speak on Food, Identity, Health, and Society (Lantern Books, 2010)

Ison, Jessica, 'Animal Abuse and Advocating for the Carceral: Critiquing Animal Abuse Registries' (2019) 8(2) Animal Studies Journal 55 doi.org/10.14453/ asj.v8i2.7

Ison, Jessica and JL Schatz, 'Introduction: Queering the Ecofeminist Tradition' (2016) 9(3) Green Theory \& Praxis Journal 4

Kean, Hilda, 'Human and Animal Space in Historic "Pet" Cemeteries in London, New York and Paris' in Jay Johnston and Fiona Probyn-Rapsey (eds), Animal Death (Sydney University Press, 2013) 21 doi.org/10.2307/j.ctt1gxxpvf.8

Kim, Claire Jean, Dangerous Crossings: Race, Species, and Nature in a Multicultural Age (Cambridge University Press, 2015)

Li Chien-hui, 'An Unnatural Alliance? Political Radicalism and the Animal Defence Movement in Late Victorian and Edwardian Britain' (2012) 42(1) EurAmerica 1

Mayer, Jed, 'Ways of Reading Animals in Victorian Literature, Culture and Science' (2010) 7(5) Literature Compass 347 doi.org/10.1111/j.1741-4113.2009. 00697.x

Mazzeno, Laurence W and Ronald D Morrison, 'Introduction' in Laurence W Mazzeno and Ronald D Morrison (eds), Animals in Victorian Literature and Culture: Contexts for Criticism (Palgrave Macmillan UK, 2017) 1 doi.org/ 10.1057/978-1-137-60219-0_1

McKinney, Karyn, 'Emotion Work of Coping with the Death of a Companion Animal' (2019) 27(1) Society \& Animals 109 doi.org/10.1163/1568530612341586 
Morris, Patricia, 'Managing Pet Owners' Guilt and Grief in Veterinary Euthanasia Encounters' (2012) 41(3) Journal of Contemporary Ethnography 337 doi.org/ $10.1177 / 0891241611435099$

Munro, Lyle, Compassionate Beasts: The Quest for Animal Rights (Praeger, 2001)

National Health and Medical Research Council, Australian Code of Practice for the Care and Use of Animals for Scientific Purposes (Report, 7th ed, 2004)

Nocella, Anthony J II et al (eds), Defining Critical Animal Studies: An Intersectional Social Justice Approach for Liberation (Peter Lang Publishing, 2014) doi.org/ 10.3726/978-1-4539-1230-0

Pachirat, Timothy, Every Twelve Seconds: Industrialized Slaughter and the Politics of Sight (Yale University Press, 2011)

Palmer, Clare Alexandra, 'Killing Animals in Animal Shelters' in Animal Studies Group (ed), Killing Animals (University of Illinois Press, 2006) 170

Pellow, David Naguib, Total Liberation: The Power and Promise of Animal Rights and the Radical Earth Movement (University of Minnesota Press) doi.org/ 10.5749/minnesota/9780816687763.001.0001

Pendergrast, Nick, 'Live Animal Export, Humane Slaughter and Media Hegemony' (2015) 4(1) Animal Studies Journal 99

Perkins, David, Romanticism and Animal Rights (Cambridge University Press, 2003)

Pręgowski, Michał Piotr, 'All the World and a Little Bit More: Pet Cemetery Practices and Contemporary Relations between Humans and Their Companion Animals' in Margo DeMello (ed), Mourning Animals: Rituals and Practices Surrounding Animal Death (Michigan State University Press, 2016)

Probyn-Rapsey, Fiona, 'Five Propositions on Ferals' (2016) 6 Feral Feminisms $<$ https://feralfeminisms.com/five-propositions-on-ferals/>

Probyn-Rapsey, Fiona and Jay Johnston, Animal Death (Sydney University Press, 2013)

Regan, Tom, The Case for Animal Rights (University of California Press, 1983)

Reilly, JS (ed), Euthanasia of Animals Used for Scientific Purposes (Australian \& New Zealand Council for the Care of Animals in Research and Teaching, 2nd ed, 2001)

Ross, Cheri Barton, Pet Loss and Human Emotion: A Guide to Recovery, ed Jane Baron-Sorensen (Taylor \& Francis, 2nd ed, 2013) 
Shukin, Nicole, Animal Capital: Rendering Life in Biopolitical Times (University of Minnesota Press, 2009)

Taylor, Nik and Tania Signal (eds), Theorizing Animals: Re-Thinking Humanimal Relations (Brill, 2011) doi.org/10.1163/ej.9789004202429.i-294

Tiplady, Catherine, Animal Abuse: Helping Animals and People (CABI, 2013)

Twine, Richard, 'Intersectional Disgust? Animals and (Eco)Feminism' (2010) 20(3) Feminism \& Psychology 397 doi.org/10.1177/0959353510368284

Wadiwel, Dinesh Joseph, The War Against Animals (Brill Rodopi, 2015)

Weil, Kari, 'A Report on the Animal Turn' (2010) 21(2) differences 1 doi.org/ 10.1215/10407391-2010-001

Wolfensohn, Sarah and Maggie Lloyd, Handbook of Laboratory Animal Management and Welfare (Blackwell Science, 2nd ed, 1998)

Zhu, Yi and Min Liu, 'Discussion of the Metropolis Pet Funeral and Burial Service' in Ying Zhang (ed), Future Communication, Computing, Control and Management: Volume 2 (Springer, 2012) 267 doi.org/10.1007/978-3-64227314-8_38

\section{B Legislation}

Prevention of Cruelty to Animals Act 1986 (Vic)

\section{Other}

Allavena, Rachel, 'Why You Shouldn't Bury Your Pet in the Backyard', ABC News (online, 19 March 2019) <https:/www.abc.net.au/news/2019-03-19/whyyou-shouldn\%E2\%80\%99t-bury-your-pet-in-the-backyard/10915772>

Andersen, Kip, 'The Facts', Cowspiracy: The Sustainability Secret (Web Page) $<$ https://www.cowspiracy.com/facts>

Animal Rights, 'Animals Are Not Ours Memorial', Vimeo (Video, 7 October 2013) <https://vimeo.com/76382879>

Australian Bureau of Statistics, Livestock and Meat, Australia, June 2020 (Catalogue No 7218.0.55.001, 8 May 2020) <https:/www.abs.gov.au/statistics/industry/ agriculture/livestock-and-meat-australia/latest-release>

'Companion Animals', Animals Australia (Web Page, 13 August 2019) <https:// www.animalsaustralia.org/issues/companion_animals.php> 
'End-of-Life Services', Animal Humane Society (Web Page) <https://www.animal humanesociety.org/health/end-life-services>

'Euthanasia', Australian Veterinary Association (Web Page, 10 August 2007) <https:/www.ava.com.au/policy-advocacy/policies/euthanasia/euthanasia/>

Kleinfeldt, Alexandra, 'Brief Summary of Animal Euthanasia', Animal Legal \& Historical Center (Web Page, 2017) < https://www.animallaw.info/intro/ animal-euthanasia>

Merriam-Webster Dictionary (online at 24 June 2021) 'Euthanasia', <https:// www.merriam-webster.com/dictionary/euthanasia>

'Our History', RSPCA UK (Web Page) < https://www.rspca.org.uk/whatwedo/ whoweare/history>

Pilat, Lauren, “"Humanely Euthanised”: Roos to Be Killed to Make Way for Development South of Perth', WAtoday (online, 28 January 2019) <https:// www.watoday.com.au/national/western-australia/humanely-euthanisedroos-to-be-killed-to-make-way-for-development-south-of-perth-20190128p50u4u.html>

RSCPA Australia, RSPCA Australia National Statistics 2019-2020 (Report) <https://www.rspca.org.au/sites/default/files/RSPCA $\% 20$ Australia $\% 20$ Annual\%20Statistics\%202019-2020.pdf>

'Statistics', No KillAdvocacy Center (Web Page) <https://www.nokilladvocacycenter. org/statistics.html>

'Suicide', Australian Veterinary Association (Web Page) < https://www.ava.com.au/ member-services/vethealth/suicide/>

'When is the Right Time for Euthanasia?', Living With Pet Bereavement (Web Page) <https://livingwithpetbereavement.com/is-the-time-right $\% 3 \mathrm{~F}>$

Wills, Matthew, 'The Invention of Pets', JSTOR Daily (Blog Post, 28 January $2017)<$ https://daily.jstor.org/the-invention-of-pets/> 
This text is taken from Voluntary Assisted Dying: Law? Health? Justice?, edited by Daniel J Fleming and David J Carter, published 2022 by ANU Press, The Australian National University, Canberra, Australia.

doi.org/10.22459/VAD.2022.06 